\title{
BM Global Health Malaria vector control in sub-Saharan Africa in the time of COVID-19: no room for complacency
}

Carlos A Guerra (D , , ${ }^{1}$ Olivier Tresor Donfack, ${ }^{2}$ Liberato Motobe Vaz, ${ }^{2}$ José A Mba Nlang, ${ }^{2}$ Lucas O Nze Nchama, ${ }^{2}$ Jeremías N Mba Eyono, ${ }^{2}$ Matilde Riloha Rivas, ${ }^{3}$ Wonder P Phiri, ${ }^{2}$ Christopher Schwabe, ${ }^{4}$ Edward Aldrich, ${ }^{1}$ Josea Ratsirarson, ${ }^{1}$ Godwin Fuseini, ${ }^{2}$ Guillermo A García (D) ${ }^{1}$

To cite: Guerra CA, Tresor Donfack 0, Motobe Vaz L, et al. Malaria vector control in sub-Saharan Africa in the time of COVID-19: no room for complacency. BMJ Global Health 2020;5:e003880. doi:10.1136/ bmjgh-2020-003880

Received 2 September 2020 Revised 5 September 2020 Accepted 7 September 2020
Check for updates

(C) Author(s) (or their employer(s)) 2020. Re-use permitted under CC BY-NC. No commercial re-use. See rights and permissions. Published by BMJ.

${ }^{1}$ International Division, Medical Care Development, Silver Spring, Maryland, USA 2International Division, Medical Care Development, Malabo, Equatorial Guinea ${ }^{3}$ National Malaria Control Programme, Ministry of Health and Social Welfare, Malabo, Equatorial Guinea

${ }^{4}$ Medical Care Development, Augusta, Maine, USA

Correspondence to Dr Carlos A Guerra; cguerra@mcd.org
The COVID-19 pandemic can potentially bring public health interventions in lowincome countries to a collapse. In sub-Saharan Africa (SSA), the saturation of health systems can expose pre-existing fragilities and exacerbate the myriad health problems afflicting human populations. In particular, SSA bears the brunt of malaria, ${ }^{1}$ which caused around 200 million cases and 400000 deaths in 2018, mostly in young children. ${ }^{2}$

The challenges for health systems of coping with COVID-19 and malaria at the same time are onerous due to complex interactions between both diseases. Malaria and COVID-19 can be symptomatically similar, complicating differential diagnosis. Therefore, malaria infections may go undiagnosed in people presenting fever and testing positive for COVID-19, potentially causing malaria cases to go untreated. In another scenario, symptomatic, malaria-infected individuals could be deterred from seeking healthcare due to fear of COVID-19 infection or could be denied treatment if health centres and hospitals were overwhelmed. Perhaps most importantly, the increasing demand for resources to curb COVID-19 and the curtailment of economic activities driven by the pandemic could lead to substantial reductions in government revenues, ${ }^{3}$ undermining their ability to finance essential social services, including life-saving malaria vector control interventions. Here, we focus our discussion on vector control for preventing malaria in SSA in the context of the current pandemic, neither neglecting the importance of other essential malaria health services and interventions nor the importance of malaria in other endemic areas.

The scaling-up of vector control, chiefly insecticide-treated nets (ITN) and indoor residual spraying (IRS), was the main driver
Summary box

In sub-Saharan Africa (SSA), the COVID-19 pandemic could cause major disruptions to the delivery of malaria vector control interventions.

- Such disruptions could potentially lead to significant increases in malaria morbidity and mortality in the region.

- The challenges for sustaining malaria vector control are multiple, from funding shortages to obstacles during implementation.

- The latter are more difficult to appreciate and are described from experience in the field.

- There is a need for major commitment from governments, organisations and individuals to avert a malaria public health disaster in SSA

for the significant reductions of malaria burden in SSA in the past two decades. ${ }^{4}$ Vector control is normally targeted to the populations at the highest risk of malaria transmission. IRS should be delivered annually before the beginning of the transmission seasons. ${ }^{5}$ ITN, on the other hand, should be distributed through triennial mass campaigns and maintained over time through continuous distribution channels such as schools and antenatal clinics. ${ }^{6}$

During the pandemic, these interventions may be hindered by reallocation of limited resources to COVID-19 response and disruptions in supply chains of IRS insecticides and ITN. Moreover, vector control implementation may be hampered by social distancing and mobility restrictions as well as by limited community acceptance of these interventions over fears of viral contagion (IRS, in particular, requires workers to enter houses to spray the inner walls, hence it can be perceived as invasive). 
Modelling has estimated that, given worst-case scenarios of disruptions of malaria interventions, including ITN and IRS, there could be up to a fourfold increase in malaria mortality in the region within the next year or more malaria deaths in 2020 than all malaria deaths reported globally in $2000 .{ }^{78}$ This would represent rolling back 20 years of progress in malaria control. Even considering less extreme scenarios, the burden of malaria in SSA during the pandemic will remain greater than that of COVID-19 itself, and plausibly worse than it would have been in the absence of the pandemic.

The ultimate objective for malaria-endemic countries should be to sustain vector control interventions at high coverage to allow for community-level protection (canonically, the recommended coverage has been to protect at least $80 \%$ of the population). Some key strategies to achieve this critical goal are proposed (box 1). We obtained available country-specific information on the scheduling and completion of vector control campaigns in SSA in $2020^{9}{ }^{10}$ (table 1). With respect to IRS, these data show that, by the end of August, at least 10 countries had completed IRS rounds, spray campaigns were ongoing in 2 and 5 had definitive plans for implementing rounds later in the year. Sixteen other countries had scheduled IRS rounds this year but no information on these was publicly available. ${ }^{7}$

Regarding ITN, at least seven countries had successfully completed distribution by the end of August 2020. Twelve other countries had partially completed campaigns or had rescheduled them for later in the year. A total of 34.3 million ITN had been distributed, protecting 60.0 million people in the targeted areas and at least another 87.9 million ITN are planned for distribution, targeting another 134.1 million people. At the time of writing, five countries specifically reported delays due to COVID-19

Box 1 Strategies required for sustaining malaria vector control interventions during the COVID-19 pandemic

- Ensure that funding for malaria control activities remains in place considering increased demand of additional resources to carry out activities.

- Secure timely procurement of commodities (mainly insecticidetreated nets and indoor residual spraying insecticides) and personal protective equipment for frontline workers.

- Implement training programmes according to new guidelines that consider the risks of COVID-19 transmission during control activities and ensure compliance of frontline workers with established COVID-19 prevention protocols.

- Reinforce social behaviour change and communication campaigns to increase acceptance of vector control by the community.

- Facilitate remote technical assistance for the implementation of interventions.

- Implement adaptive management of vector control allowing recurrent review of strategic plans in light of unforeseen circumstances during the pandemic.

- Engage community leaders and authorities in strategic plans in order to facilitate community acceptance of interventions.
Table 1 State of ITN distribution and IRS campaigns in 2020 among malaria-endemic countries of SSA at the time of writing

\begin{tabular}{|c|c|c|}
\hline Intervention & $\begin{array}{l}\text { ITN } \\
\text { distribution }\end{array}$ & IRS round \\
\hline $\begin{array}{l}\text { Planned countries, according to } \\
\mathrm{WHO}^{7}(\mathrm{n})\end{array}$ & 28 & 33 \\
\hline $\begin{array}{l}\text { Countries with available data (n) } \\
\text { (PAR (millions))§ }\end{array}$ & 19(562.3) & $17(460.6)$ \\
\hline Completed countries (n) & 7 & 10 \\
\hline Ongoing countries (n) & 5 & 2 \\
\hline Scheduled countries ( $n$ ) & 7 & 5 \\
\hline $\begin{array}{l}\text { Population targeted (million } \\
\text { people) }(\% \text { of PAR) }\end{array}$ & $205.1(36.5)$ & NAł \\
\hline $\begin{array}{l}\text { Population protected (million } \\
\text { people) }(\% \text { of PAR) } \dagger\end{array}$ & $60.0(10.7)$ & NA \\
\hline $\begin{array}{l}\text { Population protected/targeted } \\
(\%)^{\star} \dagger\end{array}$ & 29.3 & NA $\ddagger$ \\
\hline $\begin{array}{l}\text { ITN procured in } 2020 \text { (million } \\
\text { nets) }\end{array}$ & 90.7 & - \\
\hline $\begin{array}{l}\text { ITN confirmed for distribution } \\
\text { (million nets) }\end{array}$ & 122.2 & - \\
\hline $\begin{array}{l}\text { ITN already distributed (million } \\
\text { nets) } \dagger\end{array}$ & 34.3 & - \\
\hline
\end{tabular}

Specific, country-level data were obtained through online resources and personal communication with implementing agencies (PMI VectorLink Project for IRS (https://pmivectorlink. org) and The Alliance for Malaria Prevention for ITN (https:// allianceformalariaprevention.com). Planned and available data country counts include Equatorial Guinea to account for interventions implemented on Bioko Island.

*Data available for 16 countries at the time of writing. †Data available for five countries that had completed the scheduled campaigns and for four that had ongoing ITN distributions at the time of writing.

‡NA; no country-specific data on populations targeted and protected were available at the time of writing.

§Population at risk of malaria, 2018 estimate.

IRS, indoor residual spraying; ITN, insecticide-treated nets; PAR, Population at risk; SSA, sub-Saharan Africa;

IRS, indoor residual spraying; ITN, insecticide-treated nets; PAR, Population at risk; SSA, sub-Saharan Africa.

and one had postponed distribution for 2021. Another 10 countries had planned ITN distributions in 2020, ${ }^{7}$ but we could find no information on these campaigns. Importantly, 90.7 million ITN had been procured in the first half of 2020, a figure comparable to the average net procurement by quarter in 2018 (43 million) but lower than in 2019 (53 million).

These figures are encouraging as they show that countries are pushing for sustaining vector control despite the dire circumstances determined by the COVID-19 crisis. They also reveal, however, that much work is still needed to protect the lives of millions of people at risk of malaria in SSA. For instance, in Nigeria, the SSA country with the highest population at risk of malaria ( $>200$ million people), only $11.1 \%$ of the 22.7 million nets in the 
distribution plans have been so far distributed. Disruptions to ongoing campaigns would block 34 million people access to a life-saving bed net. Mozambique has scheduled both IRS and ITN in 2020, yet none of the campaigns had started at the time of writing. The Mozambican population targeted to receive ITN is 20.9 million, or roughly $70 \%$ of the population at risk of malaria in the country. The stakes are high.

What the figures fail to convey are the intricate difficulties that malaria control programmes are facing when implementing vector control interventions during the pandemic. Our own work on Bioko Island, Equatorial Guinea, helps illustrate these challenges to better grasp the complexity of the situation. Between February and July 2020, both IRS and ITN campaigns were conducted on Bioko given that government and donor funding were prioritised while additionally supporting the COVID-19 response. The vector control teams were trained for best practices to reduce the risk of viral infection, including transmission prevention strategies, social distancing during activities and sanitisation protocols. All field workers were equipped with requisite personal protective equipment. In March 2020, the government declared a countrywide state of emergency and interdicted mobility between districts. Later on in the campaign, several IRS operators tested positive for COVID-19 and had to isolate, significantly reducing the workforce. Social distancing measures required more time and resources to mobilise teams. In addition, increased community refusal to spray operations and mobility interdiction forced repeated changes to deployment plans.

Thanks to the ability to quickly adapt operations in response to these changing circumstances, vector control interventions on Bioko Island were neither seriously delayed nor interrupted, but the IRS campaign did suffer significant setbacks, with decreased productivity (each worker sprayed 3.2 houses per day in 2020 compared with an average of 4.1 houses per worker per day in the previous three rounds) and suboptimal coverage (74.6\% of households were sprayed in targeted communities in 2020 compared with a $79.2 \%$ average coverage in the previous three rounds). Given the less intrusive nature of ITN distribution, no major difficulties were encountered, achieving an overall coverage of $89.1 \%$ of the targeted households. These accounts attest to the huge challenges faced by vector control teams due to the COVID-19 pandemic that can threaten the completion of campaigns.

The risk of malaria resurgence often remains high in places where gains against the disease have been achieved, such as is the case in much of SSA. ${ }^{11}{ }^{12}$ This is due to the high intrinsic potential for malaria transmission, which determines that these gains are usually fragile and underscores the need to sustain vector control. ${ }^{12}$ To this end, the commitment from governments, funding agencies, non-governmental organisations and individuals to malaria control has been and continues to be instrumental during the pandemic. National malaria control programmes must commit to maintaining activities, while governments must show strong leadership and secure the necessary funds to guarantee implementation and the procurement of commodities. Funding agencies must not falter in providing critical financial resources in light of the increasing demand for supplies and the unprecedented economic contraction. International organisations must work harder to deliver the technical support required to devise new strategies and to develop necessary tools. Individuals who implement vector control must be lauded for their efforts, as they are putting their safety at risk to prevent malaria and safeguard the lives of millions of people living in malaria-endemic areas.

The worst may well be yet to come in the COVID-19 pandemic ${ }^{13}$ and its impact may take years to dissipate. ${ }^{14}$ Meanwhile, SSA countries cannot afford to relax their efforts at malaria control to avoid woeful health consequences from this disease on top of the potential devastation of COVID-19. This pandemic is very far from over and other severe pandemics will likely follow before countries achieve malaria elimination..$^{15}$ If COVID-19 is to teach us something about malaria, it should be how to keep up the fight against this old scourge during the hardest of times. This could also serve as an opportunity to boost the priority that malaria control deserves in the global public health agenda in normal times.

Twitter Carlos A Guerra @MCDItweets

Acknowledgements We would like to express our gratitude to Meghan Tammaro and Kate Stillman for sharing country-level information on completion of IRS rounds from the PMI VectorLink Project. We are grateful to Mark Donahue for providing critical comments to improve the clarity of the manuscript. We thank the National Malaria Control Programme and the Ministry of Health and Social Welfare of Equatorial Guinea, as well as Marathon Oil, Noble Energy, AMPCO (Atlantic Methanol Production Company) and the Ministry of Mines and Energy of Equatorial Guinea for their continued support of the fight against malaria on Bioko Island.

Contributors CAG conceived the idea of the manuscript and wrote the first draft CAG and GG assembled country data on IRS and ITN campaigns in sub-Saharan Africa. OTD, LMV, JAMN, LONN, JNME, MRR and GF implemented vector control interventions and contributed with details of the challenges in the field. All authors contributed to the final draft of the manuscript.

Funding The authors have not declared a specific grant for this research from any funding agency in the public, commercial or not-for-profit sectors.

Competing interests None declared.

Patient consent for publication Not required.

Provenance and peer review Not commissioned; internally peer reviewed.

Data availability statement Data are available upon request.

Open access This is an open access article distributed in accordance with the Creative Commons Attribution Non Commercial (CC BY-NC 4.0) license, which permits others to distribute, remix, adapt, build upon this work non-commercially, and license their derivative works on different terms, provided the original work is properly cited, appropriate credit is given, any changes made indicated, and the use is non-commercial. See: http://creativecommons.org/licenses/by-nc/4.0/.

\section{ORCID iDs}

Carlos A Guerra http://orcid.org/0000-0002-4069-9528

Guillermo A García http://orcid.org/0000-0002-4430-4781

\section{REFERENCES}

1 Weiss DJ, Lucas TCD, Nguyen M, et al. Mapping the global prevalence, incidence, and mortality of Plasmodium falciparum, 
2000-17: a spatial and temporal modelling study. Lancet 2019;394:322-31.

2 WHO. World malaria report 20192019.

3 Organisation for economic co-operation and development (OECD) COVID-19 in Africa. Regional socio-economic implications and policy priorities 2020:1-22.

4 Bhatt S, Weiss DJ, Cameron E, et al. The effect of malaria control on Plasmodium falciparum in Africa between 2000 and 2015. Nature 2015;526:207-11.

5 WHO. Indoor residual spraying: an operational manual for indoor residual spraying (IRS) for malaria transmission control and elimination 2015.

6 WHO. Achieving and maintaining universal coverage with longlasting insecticidal nets for malaria control 2017.

$7 \mathrm{WHO}$. The potential impact of health service disruptions on the burden of malaria: a modelling analysis for countries in sub-Saharan Africa 2020.
8 Sherrard-Smith E, Hogan AB, Hamlet A, et al. The potential public health consequences of COVID-19 on malaria in Africa. Nat Med 2020. doi:10.1038/s41591-020-1025-y. [Epub ahead of print: 07 Aug 2020].

9 US President's Malaria Initiative. Vectorlink 2020.

10 The alliance for malaria prevention 2020

11 Guerra CA, Fuseini G, Tresor Donfack O, et al. Malaria outbreak in Riaba district, Bioko Island : lessons learned. Malar J 2020:1-9.

12 Cohen JM, Smith DL, Cotter C, et al. Malaria resurgence: a systematic review and assessment of its causes. Malar $J$ 2012;11:122.

13 COVID-19: the worst may be yet to come. Lancet 2020;396:71.

14 Kissler SM, Tedijanto C, Goldstein E, et al. Projecting the transmission dynamics of SARS-CoV-2 through the postpandemic period. Science 2020;368:860-8.

15 Gavi. 10 infectious diseases that could be the next pandemic 2020 